\title{
On the Collision-Activated Fragmentation of Proferrioxamines: Evidence for a Succinimide-Mediated Mechanism*
}

\author{
Gottfried J. Feistner and Lanny L. Hsieh ${ }^{\dagger}$ \\ Beckman Research Institute of the City of Hope, Duarte, California, USA
}

\begin{abstract}
The fragmentation mechanism of acyclic proferrioxamines has been studied by tandem mass spectrometry in a triple stage quadrupole mass analyzer by using activation in the collision cell as well as in the high pressure region prior to the first mass analyzer. The data suggest that proferrioxamines fragment preferentially at the hydroxamate bonds via cyclic rearrangement to succinimide derivatives. This pattern was observed most clearly for the peracetyl derivatives, in which the influence of terminal functional groups was masked. Free amino or carboxylic acid functions may modify this basic fragmentation pattern. Using hydrogendeuterium exchange, we also were able to show that the hydrogen atoms that are "recruited" in the formation of ammonium ions are "acidic" ones from elsewhere in the molecule or the matrix. At the same time, this rules out that they originate from "activated" methylene groups, as previously proposed [de Hoffmann, E.; Stroobant, V. Biol. Mass Spectrom. 1991, 20, 142]. (J Am Soc Mass Spectrom 1995, 6, 836-846)
\end{abstract}

$\mathrm{P}$ roferrioxamines (pFOs) are microbial siderophores of the hydroxamate type. Due to their excellent metal complexation capability, they are useful as detoxification agents in iron and aluminum overload [2] and as bifunctional ligands in tumor imaging with radiolabeled antibodies [3]. Proferrioxamines may be viewed as peptides in which every second amide bond has been replaced by a hydroxamate ( $N$-hydroxy-amide) bond of opposite orientation (Figure 1). However, as will be discussed in succeeding text, the fragmentation behavior of proferrioxamines is quite different from that of peptides. Known natural proferrioxamines mainly consist of merely two basic building blocks, namely, $N$-hydroxy- $\alpha, \omega$ diamines (typically $C_{3}-C_{5}$ ) and succinic acid. We recently identified a whole family of proferrioxamines from Erwinia amylovora, the plant pathogenic bacterium that causes fire blight disease of apple and pear [4]. Most of the proferrioxamines could be identified readily by tandem mass spectrometry, which revealed the number and sizes of the constituent $\omega$ succinylamino- $N$-hydroxyaminoalkane residues. However, some proferrioxamines resisted identification because they apparently contained atypical residues. The corresponding residue masses could, unfortunately, not

Address reprint requests to Dr. Gottfried J. Feistner, 7196 Eastwood Avenue, Rancho Cucamonga, CA 91701.

- Part 11 in the series Metabolites of Erwinia; for Part 10, see ref 1. Presented, in part, at the 42nd ASMS Conference on Mass Spectrometry and Allied Topics, Chicago, Illinois, May 29-June 3, 1994.

Present address: California Institute of Technology, Mail Code 277, Pasadena, CA 91125. be determined precisely, because the fragmentation mechanism and especially the accompanying hydrogen transfer reactions were not fully understood. Our efforts to remedy this situation led to the results and conclusions presented here.

\section{Status Prior to this Investigation}

The collision-activated fragmentation of proferrioxamines was first investigated in 1991 by de Hoffmann and Stroobant [5], who limited their study to $\mathrm{pFO}_{555 \mathrm{Ac}}$ (desferal ${ }^{\mathrm{TM}}$; regarding the nomenclature, see [6] and succeeding text), the only commercially available proferrioxamine. Employing fast-atom bombardment (FAB) tandem mass spectrometry, they obtained a product ion spectrum essentially identical to the one observed by us via electrospray tandem mass spectrometry (ESI-MS/MS) (Figure 2). As de Hoffmann and Stroobant already pointed out, the interpretation of the product ion spectrum of $\mathrm{pFO}_{555 \mathrm{Ac}}$ is not straightforward, because several conceivable fragment ions are isobaric (Schemes I and II; fragment ion masses that are not observed or are of only minor abundance are given in parentheses). To reduce ambiguities in the interpretation and, specifically, to identify $N$-terminal fragments, de Hoffmann and Stroobant prepared and analyzed the $\mathrm{N}$-terminal dimethyl derivative. Their conclusion was that, in analogy to an early proposal for the fragmentation of peptides [7, 8], the fragmentation of proferrioxamines would follow pathways A and B of Scheme II. Scheme II was thought to be applicable to both the amide and hydroxamate bonds. 

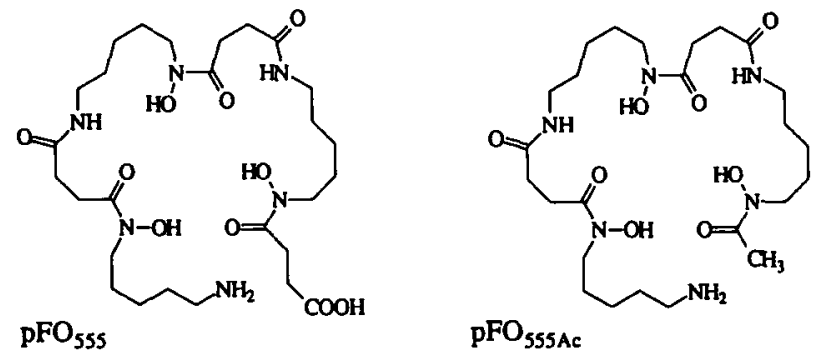

Figure 1. Chemical structure of the two proferrioxamines analyzed in this study. Metal chelation is via the hydroxamate groups. For a detailed discussion of the nomenclature of proferrioxamines, see ref 6 .

Interestingly, however, dimethylation led to a mass shift of $28 \mathrm{u}$ for only a minor fraction of putative $N$-terminal fragment ions $(m / z 201$ and 401). de Hoffmann and Stroobant therefore suggested that the majority of the $m / z 201$ and 401 ions originated from $C$-terminal fragment ions ( $m / z 243$ and 443) via cleavage between the two methylene groups of the succinyl moiety and thus loss of ketene (Scheme IIC). The loss of ketene from the $\mathrm{m} / \mathrm{z} 243$ and 443 ions could not be proven experimentally, because these ions were not present in the FAB mass spectrum. After a review of the original publication, we furthermore felt that even if the loss of ketene were to occur, the $\mathrm{m} / z 201$ and 401 ions were more likely to be internal fragment ions derived from the $m / z 243$ and 443 ions via loss of ketene from the $C$-terminal acetyl group (Scheme IID). Internal fragments were not considered by de Hoffmann and Stroobant.

Our recent detailed tandem mass spectrometric analysis of a large number of proferrioxamines [4] and

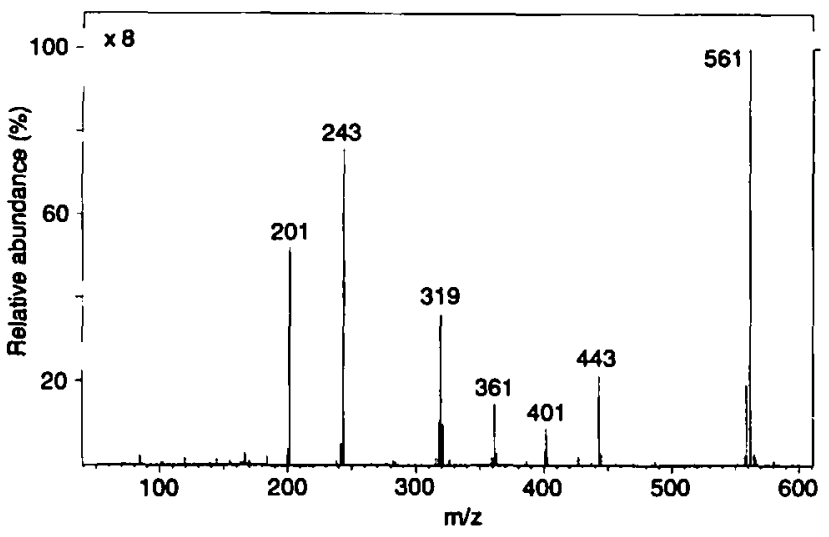

Figure 2. Single scan product ion spectrum of $\mathrm{pFO}_{555 \mathrm{Ac}}$, recorded during LC-ESI-MS/MS analysis. This spectrum is very similar to the $\mathrm{FAB}$ mass spectrum reported for $\mathrm{pFO}_{555 \mathrm{Ac}}$ earlier [5]. A collision energy ( $\left.E_{\mathrm{lab}}\right)$ of $15 \mathrm{eV}$ and a linear LC gradient of $1-91 \% \mathrm{~B}$ in $60 \mathrm{~min}$ were used $[\mathrm{A}=0.1 \%$ trifluoroacetic acid (TFA), B $=0.07 \%$ TFA in $90 \%$ acetonitrile]. In our chromatographic system [4], $\mathrm{pFO}_{555 \mathrm{Ac}}$ coelutes with $\mathrm{pFO}_{(455)}$ and $\mathrm{pFO}_{445 \mathrm{c}}$ immediately before $\mathrm{pFO}_{555}$ and $\mathrm{pFO}_{355 c}$; thus mass spectrometry, and preferably tandem mass spectrometry, is needed to distinguish between these different proferrioxamines.

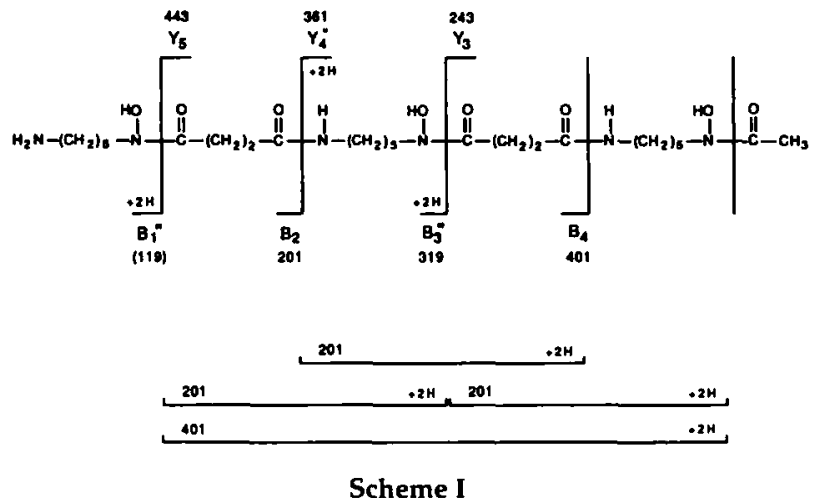

newer investigations on the fragmentation mechanism of peptides $[9,10]$ cast additional doubt on Scheme IIA-C. Thus, for peptides it was shown that one of the hydrogen transfers involves two nitrogen atoms rather than an $\alpha$-carbon and a nitrogen atom as implied by Scheme IIB (the second hydrogen atom originates from the matrix). On the other hand, the fragmentation of cyclic proferrioxamines was shown by us to involve mainly only every other amide or hydroxamate bond [4]. For example, most of the fragment ion current for $\mathrm{pFO}_{555 \mathrm{c}}$ is carried by just two fragment ions $(\mathrm{m} / \mathrm{z} 201$ and 401 ), which, in this case, must be "internal" fragments.

The selective fragmentation pattern of cyclic proferrioxamines (fragmentation at either the amide or hydroxamate bonds, but not at both) cannot be explained by Scheme II in itself. One possibility to reconcile Scheme II with the experimentally observed fragmentation pattern would be to assume considerable differences in bond dissociation energies between amide and hydroxamate bonds. However, our previous data suggested that differences in bond dissociation energies were not important (discussed further in the following text). We therefore proposed a charge-remote fragmentation mechanism [4], the essence of which is
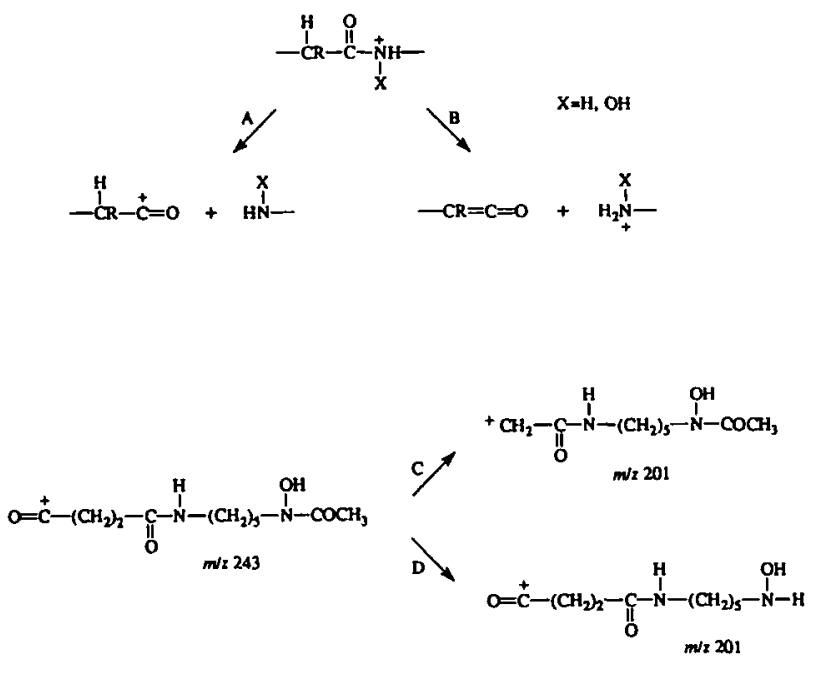

Scheme II 
shown in Scheme IIIa (reprinted by permission of John Wiley \& Sons, Ltd.). In short, the fragmentation mechanism involves hydrogen transfer from an amide to a hydroxamate nitrogen atom and the sterically and energetically favorable formation of a succinimide ring. Hydrogen transfer in the opposite direction is not possible, due to the lack of a nitrogen-bound hydrogen atom at the hydroxamate function. Scheme IIIa therefore rationalized previously available experimental data. If, in contrast, fragmentation were to occur at the site of protonation (charge-directed mechanisms; Scheme IIIb and c), no further hydrogen transfer from the "opposite" amide or hydroxamate would be needed to create a good leaving group and no selective cleavage would be expected. It is worthy of note that a (charge-driven) fragmentation mechanism that involves a five-membered cyclic intermediate, rather than the mechanisms shown in Scheme Пla and $b$, recently also has been proposed for the fragmentation of peptides [11].

As stated in the preceding text, our previous proposal for the charge-remote fragmentation mechanism (Scheme IIIa) was based on the premise that there are no or only negligible differences in the respective bond dissociation energies between amide and hydroxamate bonds. We arrived at this premise because several product ion spectra of open-chain proferrioxamines suggested that in the latter compounds cleavage of amide and hydroxamate bonds would occur with about equal abundance. (For a possible explanation of the different fragmentation behavior between cyclic and acyclic proferrioxamines, see our previous paper [4].) If this premise were incorrect, then the basis for our proposed charge-remote fragmentation mechanism would collapse. New results obtained during the course of the present study were indeed inconsistent with this premise and prompted us to take a fresh look at the fragmentation mechanism of proferrioxamines.

\section{Charge-Remote Fragmentation at Low Collision Energy}

Gross and co-workers $[12,13]$ are generally credited with convincing the mass spectrometry community of the importance of charge-remote fragmentations.
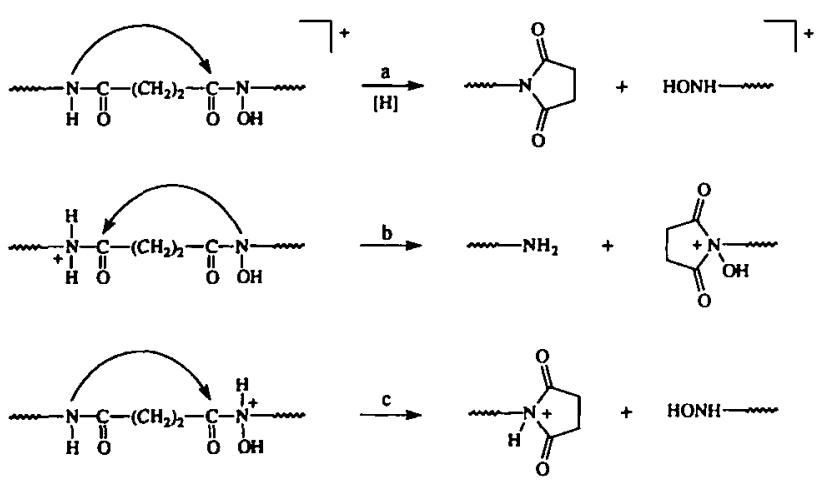

Scheme III
Charge-remote fragmentations are observed for closed-shell (even electron) ions with a localized charge and resemble thermolytic degradation reactions [14]. As may be expected, they increase in abundance with increasing center-of-mass collision energy $\left(E_{\mathrm{cm}}\right)$ and are therefore more readily observed in sector instruments at high laboratory frame collision energies $\left(E_{\mathrm{lab}}\right)$ than in quadrupole and Fourier transform ion cyclotron resonance mass spectrometers at low $E_{\text {lab }}$ $\left[E_{\mathrm{cm}}=E_{\text {lab }}\left(m_{\text {target }} /\left(m_{\text {target }}+m_{\text {analyte }}\right)\right)\right][15,16]$. In other words, charge-remote fragmentations are not observed often under our experimental conditions. However, the threshold energy for a charge-remote fragmentation is, among other factors, determined by the respective activation energy, the reaction rate, and any competing fragmentation reactions, and therefore very much compound-dependent [14, 17]. For selected compound classes, especially those that can be expected to readily undergo thermolysis, charge-remote fragmentations therefore also may be observed at low $E_{\mathrm{cm}}$ in a triple sector quadrupole mass spectrometer. The loss of alkanes from protonated 2- or 4-pentadecylpyridine at a threshold $E_{\mathrm{cm}}$ of only $1.4-3 \mathrm{eV}[17,18]$ is a relevant example. Another relevant case is that of monohydroxy-substituted unsaturated fatty acids, for which competing charge-remote and charge-driven mechanisms have been observed at $E_{\mathrm{cm}}=3 \mathrm{eV}$ [19]. In contrast, fatty acids that are only hydroxylated or only unsaturated undergo charge-remote fragmentations only under high energy collisions. Thus small changes in structure can result in considerably different threshold energies. Charge-remote fragmentations in peptides apparently require an $E_{\mathrm{cm}} \geq 10 \mathrm{eV}[14,20,21]$.

\section{Nomenclature and Convention}

To distinguish individual proferrioxamines, it is sufficient to characterize them based on the methylene units of the constituent diamines [6]. In this study we will discuss $\mathrm{pFO}_{555}\left(\mathrm{pFO} \mathrm{G}_{1}\right), \mathrm{pFO}_{555 \mathrm{Ac}}(\mathrm{pFO} \mathrm{B})$, and $\mathrm{pFO}_{555 \mathrm{c}}(\mathrm{pFO} E)$. $\mathrm{pFO}_{555}$ is acyclic and contains three diaminopentane moieties. $\mathrm{pFO}_{555 \mathrm{c}}$ is the corresponding cyclic proferrioxamine, and this is indicated by the suffix " $\mathrm{C}$ ". In $\mathrm{pFO}_{555 \mathrm{Ac}}$, the suffix " $\mathrm{Ac}^{\prime \prime}$ indicates that the $\mathrm{C}$-terminal succinic acid of $\mathrm{pFO}_{555}$ has been replaced by acetic acid.

Because product ions of proferrioxamines arise mostly from cleavage of the amide and/or hydroxamate $\mathrm{C}-\mathrm{N}$ bonds, we have adopted the nomenclature of Roepstorff and Fohlman [4, 22]. This nomenclature refers to $\mathrm{N}$ - and $\mathrm{C}$-terminal fragment ions that arise from homolytic cleavage at $\mathrm{C}-\mathrm{N}$ bonds as $\mathbf{B}$ and $\mathbf{Y}$, respectively, and indicates the gain or loss of hydrogen atoms or protons by primes to the right or left of these letters. $B$ and $Y$ in the present context do not specifically imply acylium or ammonium ions, respectively. As it turns out, however, the type of ion is nevertheless readily deduced from the presence or absence of 
double primes. Thus $B_{3}^{\prime \prime}$ and $Y_{4}^{\prime \prime}$ will refer to ammonium ions, whereas $B_{2}$ and $Y_{3}$ will refer to acylium ions.

\section{Results and Discussion}

The charge-remote fragmentation in Scheme IIIa was originally proposed for cyclic proferrioxamines [4]; however, for reasons given in the next paragraph, all investigations presented in this communication were performed on acyclic proferrioxamines, namely, $\mathrm{pFO}_{555 \mathrm{Ac}}, \mathrm{pFO}_{555}$, and the corresponding peracetyl derivatives. Because $\mathrm{pFO}_{555}$ is not commercially available, it was obtained from the culture supernatant of Hafnia alvei, an enterobacterium that previously had been reported to produce large quantities of this proferrioxamine [23].

\section{Transfer of Acidic Hydrogen Atoms}

Our first goal was to show that the formation of ammonium ions involves $\mathrm{N}-\mathrm{H}-\mathrm{N}$ rather than $\alpha \mathrm{C}-\mathrm{H}-\mathrm{N}$ transfer. Because the observed fragmentation pattern does not change upon acetylation of the hydroxamate groups [4], NO-H-N transfer was considered to be unimportant. In principle, proof for an $\mathrm{N}-\mathrm{H}-\mathrm{N}$ mechanism is readily obtainable by prior $H / D$ exchange with $\mathrm{D}_{2} \mathrm{O}$, which results in a 1 -u mass shift due to an $\mathrm{N}-\mathrm{D}-\mathrm{N}$ rather than an $\mathrm{N}-\mathrm{H}-\mathrm{N}$ transfer [10]. Unfortunately, this method cannot be used to demonstrate N-D-N transfer in cyclic proferrioxamines, for which Scheme IIIa originally had been proposed. To generate a fragment from a cyclic molecule requires at least two bond cleavages, and the net mass shift of $H$ or $D$ transfer onto the fragment at one end and removal at the other is zero.

However, we reasoned that the hydrogen transfer mechanism (origination of the hydrogen from an $\alpha$ carbon or nitrogen atom) probably would be the same in cyclic and acyclic proferrioxamines. Indeed, the results presented in the following text are consistent with the notion that not only the hydrogen transfer but the whole basic fragmentation mechanism in cyclic and acyclic proferrioxamines is the same. The tandem mass spectra of $\mathrm{pFO}_{555}$ and its fully deuteriumexchanged derivative $d_{9}-\mathrm{pFO}_{555}$ are shown in Figure 3, and the expected and observed fragment ions are illustrated in Scheme IV. Because dominant fragment ions of $\mathrm{m} / z 528$ and 326, but not $\mathrm{m} / z 527$ and 325, were observed, the $\alpha \mathrm{C}-\mathrm{H}-\mathrm{N}$ transfer mechanism cannot play more than a minor role. Instead, the data suggest that the origin of one of the transferred hydrogen atoms is a nitrogen atom or that both hydrogen atoms are derived from the matrix.

\section{Preferential Cleavage of Hydroxamate Bonds?}

Closer inspection of Figure 3 provided the first indication that, in contrast to what was previously thought
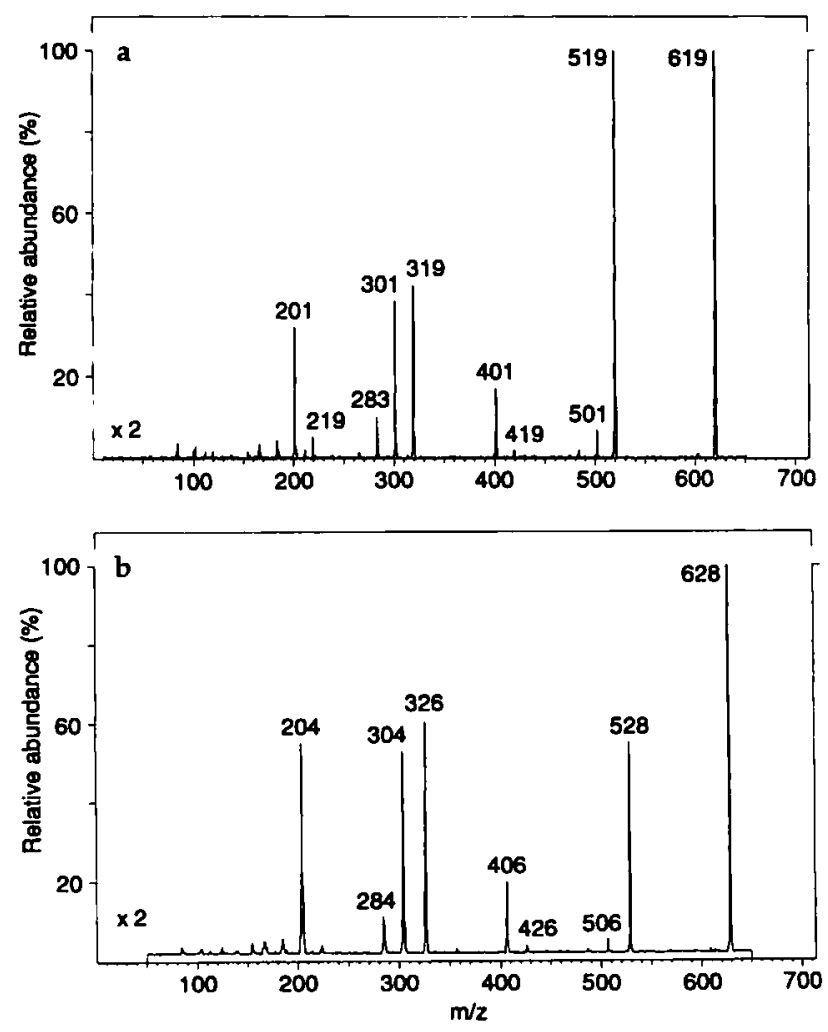

Figure 3. Product ion spectra of (a) $\mathrm{pFO}_{555}$ and (b) $\mathrm{d}_{9}-\mathrm{pFO}_{555}$, recorded during LSI-MS/MS analyses; average of 32 scans each. Collision energy $\left(E_{\mathrm{lab}}\right)$ was $10 \mathrm{eV}$; the matrices were glycerol or $d_{3}$-glycerol, respectively. When the molecular ions were generated by ESI, the product ion spectra were very similar (not shown).

(see Introduction), cleavage of hydroxamate in preference to amide bonds is facilitated in proferrioxamines in general, not just cyclic proferrioxamines. This can be deduced from the fact that the $B_{5}^{\prime \prime}(m / z 519 / 528)$ and $\mathbf{B}_{3}^{\prime \prime}(m / z$ 319/326) hydroxyammonium ions, which arise from cleavage at the hydroxamate bonds, are abundant, whereas the $Y_{4}^{\prime \prime}(m / z 419 / 426)$ and $Y_{2}^{\prime \prime}(m / z$ $219 / 224)$ ammonium ions, which arise from cleavage at the amide bonds, are of only minor abundance.
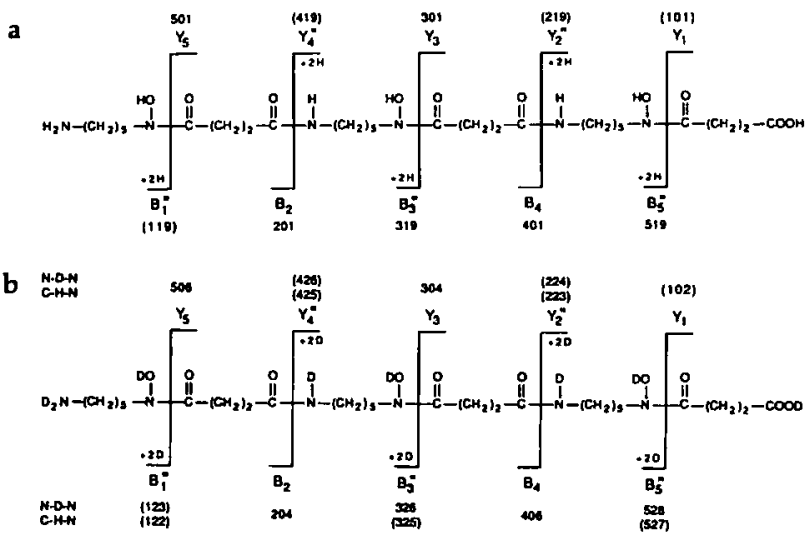

Scheme IV 
However, the evidence at this point is not unequivocal. The experimental result may alternatively arise from preferential subsequent fragmentation of the ammonium over the hydroxyammonium ions. Preferential subsequent fragmentation has been shown to account for abundance differences between peptide-derived acylium and ammonium ions [24].

We therefore looked for clues from the $Y_{5}, B_{2}, Y_{3}$, and $B_{4}$ ions at $m / z 501,201,301$ and 401, respectively. Because these are all acylium ions, their tendency to fragment further should be similar, and their relative abundance should reflect their formation rate. At first glance, there appeared to be no difference in the abundance of amide- or hydroxamate-derived acylium ions, especially because the $m / z 201$ and 401 ions give rise to strong peaks. This finding seemed to confirm our previous premise that there are no large differences in bond dissociation energies between amide and hydroxamate bonds. However, the appearance is deceptive. As will be further discussed, the $m / z 201$ and 401 ions mostly represent internal fragments.

The $Y_{2}^{\prime \prime}$ and $Y_{4}^{\prime \prime}$ ions, especially the latter, were much more abundant in our previous study [4]. Because of this and the inability to distinguish internal from $N$ terminal ions, we had arrived at the conclusion that cleavage of hydroxamate and amide bonds was about equally abundant and we proposed the charge-remote fragmentation mechanism of Scheme IIIa [4]. The reason for the discrepancy is not exactly known, but because the spectrum shown earlier represented a single scan, sampling bias is a likely explanation (orly a few product ion spectra could be collected over the duration of the corresponding capillary liquid chromatography peak). In the present study we observed considerable statistical variations between individual scans, but when eight or more scans were averaged, the relative intensity of the $\mathrm{m} / z 219$ and 419 ions was always low. (As a consequence, only averaged spectra are presented in this communication; the only exception is the product ion spectrum for $\mathrm{pFO}_{555 \mathrm{Ac}}$ (Figure $2)$, which, however, is practically identical to the previously published spectrum by de Hoffmann and Stroobant [5].) The relative intensity of the $\mathrm{m} / z 219$ and 419 ions could not be increased by increasing the collision energy ( $E_{\mathrm{lab}}$ ) from 15 to $20 \mathrm{eV}$. Also, our product ion spectrum of $\mathrm{pFO}_{555}$ shown in Figure $3 \mathrm{a}$ is consistent with one previously published by Reissbrodt et al. [23].

\section{Influence of Terminal Functional Groups}

Comparison of the collision-induced fragmentation of $\mathrm{pFO}_{555 \mathrm{Ac}}$ and $\mathrm{pFO}_{555}$ (Schemes I and IVa) shows similarities, but also differences. In either case, major fragment ions $(\mathrm{m} / \mathrm{z} 243$ and 301, and 319) arise from cleavage at the central hydroxamate bond. However, the product ion spectrum of $\mathrm{pFO}_{555 \mathrm{Ac}}$ (but not $\mathrm{pFO}_{555}$ ) features relatively abundant $Y_{5}(m / z 443)$ and $Y_{4}^{\prime \prime}$ ions $(\mathrm{m} / z 361)$, whereas the product ion spectrum of $\mathrm{pFO}_{555}$ (but not $\mathrm{pFO}_{555 \mathrm{Ac}}$ ) features an abundant $\mathrm{B}_{5}^{\prime \prime}$ ion $(\mathrm{m} / \mathrm{z}$ 519). Obviously, the nature of the termini has a pronounced influence on the fragmentation pattern. This is not unexpected. For example, as a primary site of protonation, the $N$-terminal amino function may influence the fragmentation pattern via proton transfer to amide and hydroxamate bonds, preferentially in the $N$-terminal side of the molecule [25]. On the other hand, a free $C$-terminus may override the influence of a free $N$-terminus due to the fact that a free carboxylic acid is a stronger proton donor than an ammonium ion.

\section{Evidence Against Prominent Fragmentation at Amide Bonds}

To deduce the "basic" fragmentation pattern common to all proferrioxamines, we decided to eliminate the influence of the free amino terminus through acetylation. Because $\mathrm{pFO}_{555 \mathrm{Ac}}$ also does not have a free carboxy terminus, we felt that at least $\mathrm{Ac}-\mathrm{pFO}_{555 \mathrm{Ac}}$ should display a "pure backbone fragmentation pattern." The corresponding fragmentation mechanism also should be representative for cyclic proferrioxamines because the latter may be expected to behave as infinitely long linear proferrioxamines. We had shown previously that acetylation of the hydroxamate functions does not affect the fragmentation pattern of proferrioxamines [4]. The acyclic proferrioxamines could therefore conveniently be peracetylated. The corresponding product ion spectra, which are shown in Figure 4, basically feature only four fragment ions each. Thus, as expected, the fragmentation behavior of the acetylated acyclic proferrioxamines approaches the simple fragmentation behavior of cyclic proferrioxamines. The observed fragments can all be rationalized on the basis of cleavage at the hydroxamate groups only (Scheme Va and b). We conclude that infinitely long (or cyclic) proferrioxamines hardly fragment at the amide bonds.
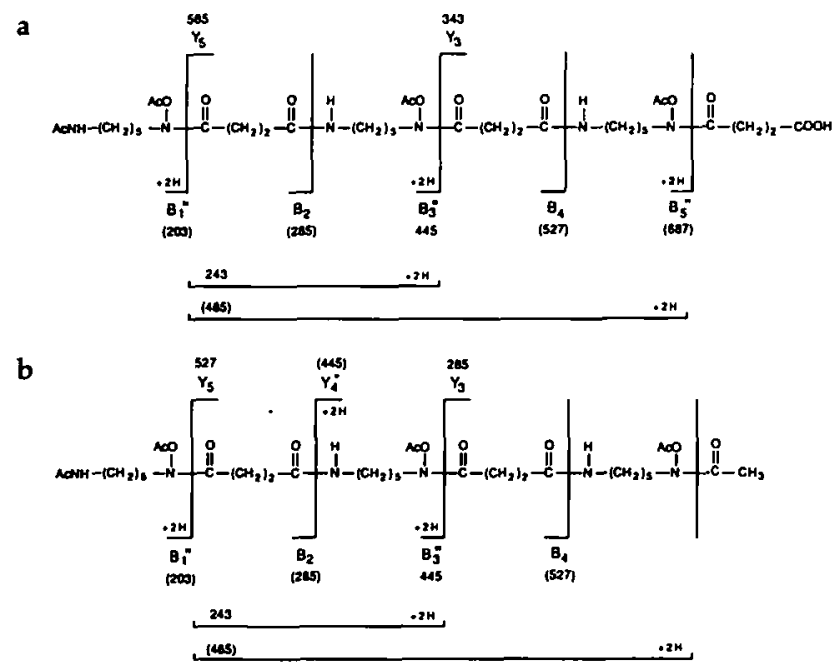

Scheme V 

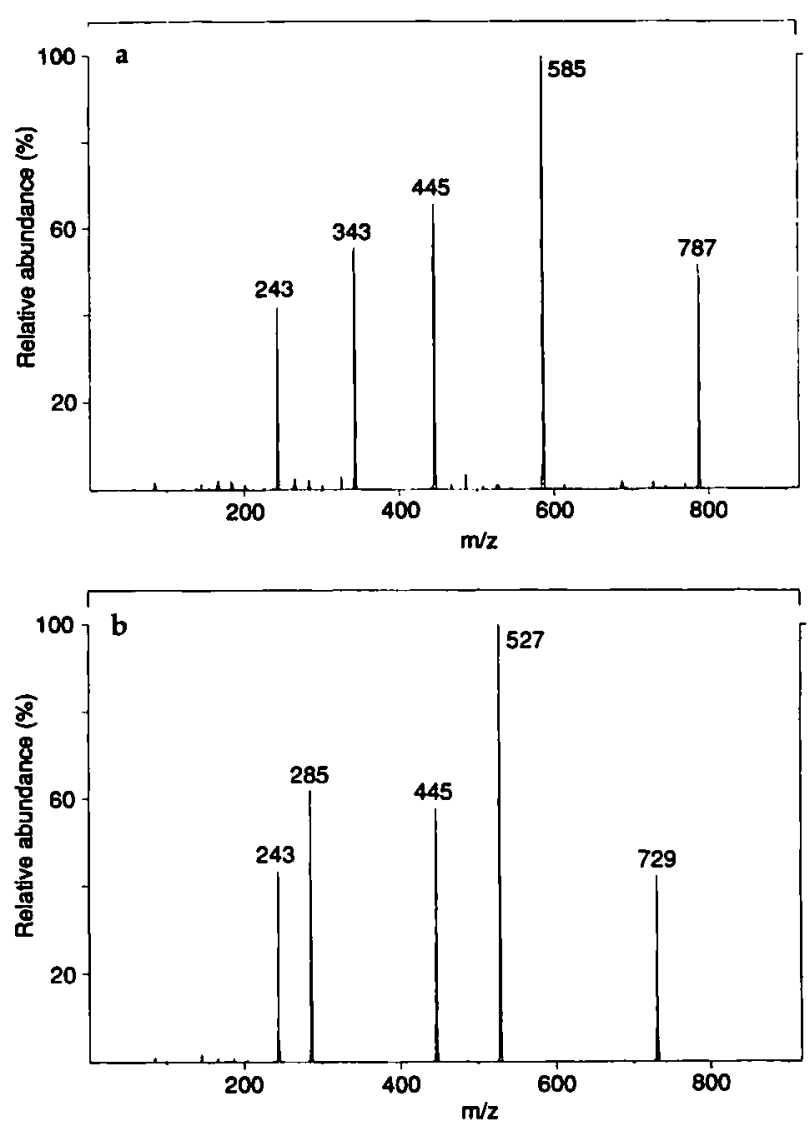

Figure 4. Product ion spectra of (a) $\mathrm{Ac}_{4}-\mathrm{pFO}_{555}$ and (b) $\mathrm{Ac}_{4}-$ $\mathrm{pFO}_{555 \mathrm{Ac}}$, recorded during LC-ESI-MS/MS analyses; average of nine and five scans, respectively. The collision energy $\left(E_{\mathrm{lab}}\right)$ was $15 \mathrm{eV}$; the LC gradients were $2-92 \% \mathrm{~B}$ in 20 and $10 \mathrm{~min}$, respectively.

The spectra also allow us to settle the question whether the $m / z 201$ and 401 ions discussed in the foregoing text are $N$-terminal or internal fragment ions. A definitive answer is possible because after peracetylation, the $\mathrm{B}_{2} / \mathrm{B}_{4}$ ions (diacetylated, $\mathrm{m} / \mathrm{z}$ $285 / 527$ ) and the internal fragment ions (monoacetylated, $m / z 243 / 485$ ) have different masses. Because essentially no $m / z 285$ and 527 fragment ions are observed for $\mathrm{Ac}_{4}-\mathrm{pFO}_{555}, \mathrm{~N}$-terminal fragment ions that arise from cleavage at amide bonds can be largely excluded. This is consistent with the product ion spectrum obtained for $\mathrm{N}^{\omega}-\mathrm{Me}_{2}-\mathrm{pFO}_{555 \mathrm{Ac}}$ by de Hoffmann and Stroobant [5] (see foregoing discussion). The product ion spectrum of $\mathrm{Ac}_{4}-\mathrm{pFO}_{555 \mathrm{Ac}}$ by itself does not allow this conclusion because in this particular case, the $N$-terminal $B_{2}$ and $B_{4}$ ions are isobaric with the $C$-terminal $Y_{3}$ and $Y_{5}$ fragment ions, respectively. However, taken together, the highly analogous product ion spectra of $\mathrm{Ac}_{4}-\mathrm{pFO}_{555}$ and $\mathrm{Ac}_{4}-\mathrm{pFO}_{555 \mathrm{Ac}}$ suggest that the fragmentation mechanism for both compounds is identical and that the free carboxylic acid terminus in $\mathrm{Ac}_{4}-\mathrm{pFO}_{555}$ is largely without influence.

\section{Fragmentation Pathways}

Sequential fragment ion analyses for the peracetyl derivatives revealed that the overall fragmentation process occurs in three stages. The first generation ions, that is, the $m / z 585$ and $445\left(\mathrm{Ac}_{4}-\mathrm{pFO}_{555}\right)$ and $\mathrm{m} / z 527$ and 445 ions $\left(\mathrm{Ac}_{4}-\mathrm{pFO}_{555 \mathrm{Ac}}\right)$, were already abundant in the conventional mass spectra [liquid chromatography-electrospray ionization mass spectrometry (LC-ESI-MS); no forced collision-activated dissociation (CAD); not shown]. Obviously, formation of these ions requires very little activation energy. The second generation fragment ions, $m / z 343 / 285$ and 243 , were only observed following CAD in either the collision cell or in the high pressure region adjacent to the ESI source. Further increase in internal energy led to numerous third generation fragment ions that were useful to establish ion structures (see following text). To determine the origin of individual second generation fragment ions, the fate of the primary fragment ions was studied by LC-ESI-MS/MS. The corresponding spectra are shown in Figure 5. Clearly, the first generation fragment ions all loose a neutral or protonated $\omega$-succinimido- $N$-acetoxy-aminopentane moiety [-242 u or $m / z 243$ (a) (Scheme VI), respectively], that is, the $m / z 343$ and 285 ions originate from the $\mathrm{m} / z 585$ and 527 ions, respectively, and the $\mathrm{m} / z 243$ ions mostly derive from the $\mathrm{m} / \mathrm{z} 445$ ions.

The tandem mass spectra of the molecular ion of $\mathrm{Ac}_{4}-\mathrm{pFO}_{555}$ and its $m / z 585$ product ion also are proof against significant cleavage between the two methylene groups of a succinyl moiety as proposed by de Hoffmann and Stroobant [5]. If such fragmentation would occur, one would expect to observe a $\mathrm{m} / \mathrm{z} 301$ $(343-42)$ ion. However, at moderate collision energy $\left(E_{\text {lab }}=15 \mathrm{eV}\right)$, which produces abundant $\mathrm{m} / \mathrm{z} 201$ ions in the product ion spectrum of $\mathrm{pFO}_{555 \mathrm{Ac}}$ (Figure 2 ), there is only a very small $m / z 301$ ion (Figures $4 a$ and $5 \mathrm{a}$ ). Instead, one observes a prominent loss of succinic anhydride $(343-243=100 \mathrm{u})$, consistent with our expectation that the loss of ketene in $\mathrm{pFO}_{555 \mathrm{Ac}}$ is from the $\mathrm{C}$-terminus.

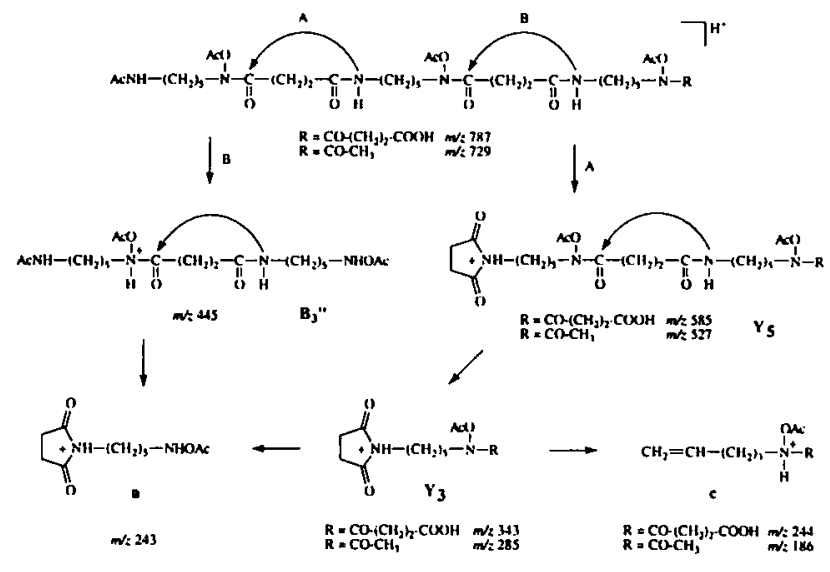

Scheme VI 

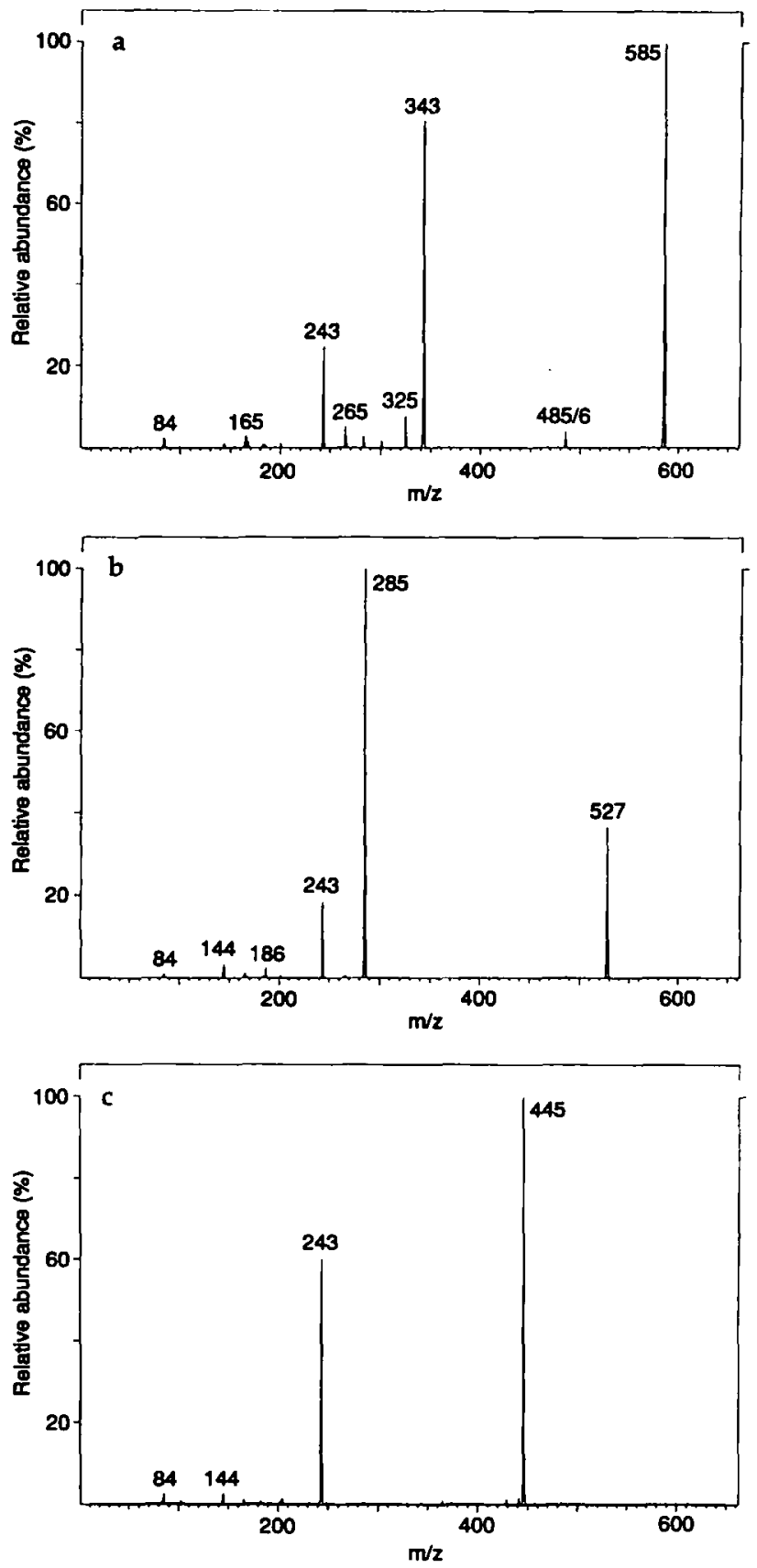

Figure 5. Product ion spectra of first generation fragment ions of $\mathrm{Ac}_{4}-\mathrm{pFO}_{555}$ and $\mathrm{Ac}_{4}-\mathrm{pFO}_{555 \mathrm{Ac}}$, that is, (a) $\mathrm{m} / z$ 585, (b) $\mathrm{m} / \mathrm{z}$ 527, and (c) $m / z$ 445, recorded during LC-ESI-MS/MS analyses; average of 8,16 , and 9 scans, respectively. The collision energy $\left(E_{\mathrm{lab}}\right)$ was $15 \mathrm{eV}$; the LC gradient was $2-92 \% \mathrm{~B}$ in $10 \mathrm{~min}$.

\section{Evidence for $\omega$-Succinimido-N-Acetoxy-Aminopentane}

Because the $\omega$-succinimido- $N$-acetoxy-aminopentane fragment apparently plays such an important role, it was of interest to confirm its structure through its product ion spectrum. Theoretically, the $m / z 243$ ion also could be the isobaric $N^{a}$-acetoxy- $N^{a}$-w-aminopentyl-succinimidium ion $\mathbf{b}$ (Scheme VII), that is, an ion in which the acetoxy group of a is shifted to the succin- a

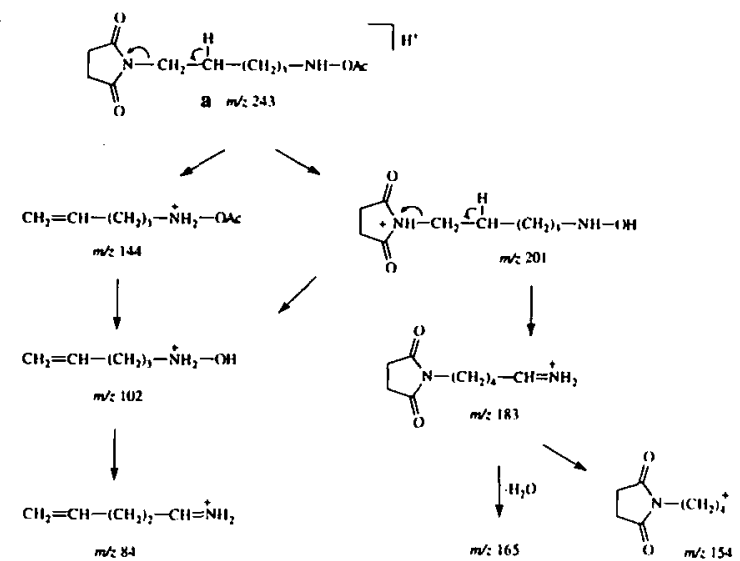

b

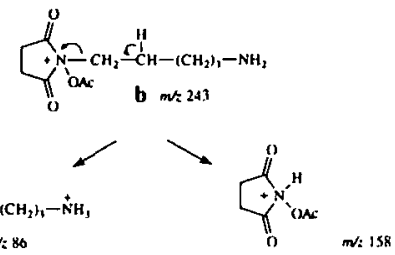

Scheme VII

imide ring. $\mathbf{b}$ could arise from the attack of a hydroxamate nitrogen at an amide carbonyl group. To acquire the respective product ion spectrum, the $m / z 243$ ion was generated by CAD at the source-analyzer interface and then subjected to tandem mass spectrometry (LC-ESI-CAD-MS-CAD-MS). The product ion spectrum was essentially the same regardless of whether the $m / z 243$ ion was derived from $\mathrm{pFO}_{555}$ or $\mathrm{pFO}_{555 \mathrm{Ac}}$ consistent with the notion that the $m / z 243$ ion represents a common fragment ion.

All product ions that would be expected from fragmentation of a were indeed observed (Figure 6a and Scheme VII), whereas ions that would be expected from fragmentation of $\mathbf{b}(\mathrm{m} / \mathrm{z} 158$ and 86$)$ were not observed. In particular, the putative succinimide ring is corroborated by a prominent loss of $99 \mathrm{u}(\mathrm{m} / z 243$ to 144 and 201 to 102) and a peak for protonated succinimide at $m / z 100$. Other product ions can be explained readily by loss of ketene or acetic acid, water, or $\mathrm{CH}_{2} \mathrm{NH}$, and therefore also support structure a. The $m / z 165$ ion probably arises from loss of water from the $m / z 183$ ion. Although the corresponding mechanism is not known, the formation of a Schiff base is conceivable. Structure a furthermore is consistent with an elemental composition of $\mathrm{C}_{11} \mathrm{H}_{19} \mathrm{O}_{4} \mathrm{~N}_{2}$ and four double bond equivalents. Three double bond equivalents correspond to the three carbonyl functions, whereas the fourth double bond equivalent can be satisfied by the cyclic succinimido structure. We thus conclude that the $m / z 243$ ion is an internal fragment ion of structure a with the proton perhaps shared between the two nitrogen atoms.

a can arise from the $N$-terminal $\mathrm{m} / \mathrm{z} 445$ ion or from the C-terminal $m / z \quad 343$ and 285 ions, that 

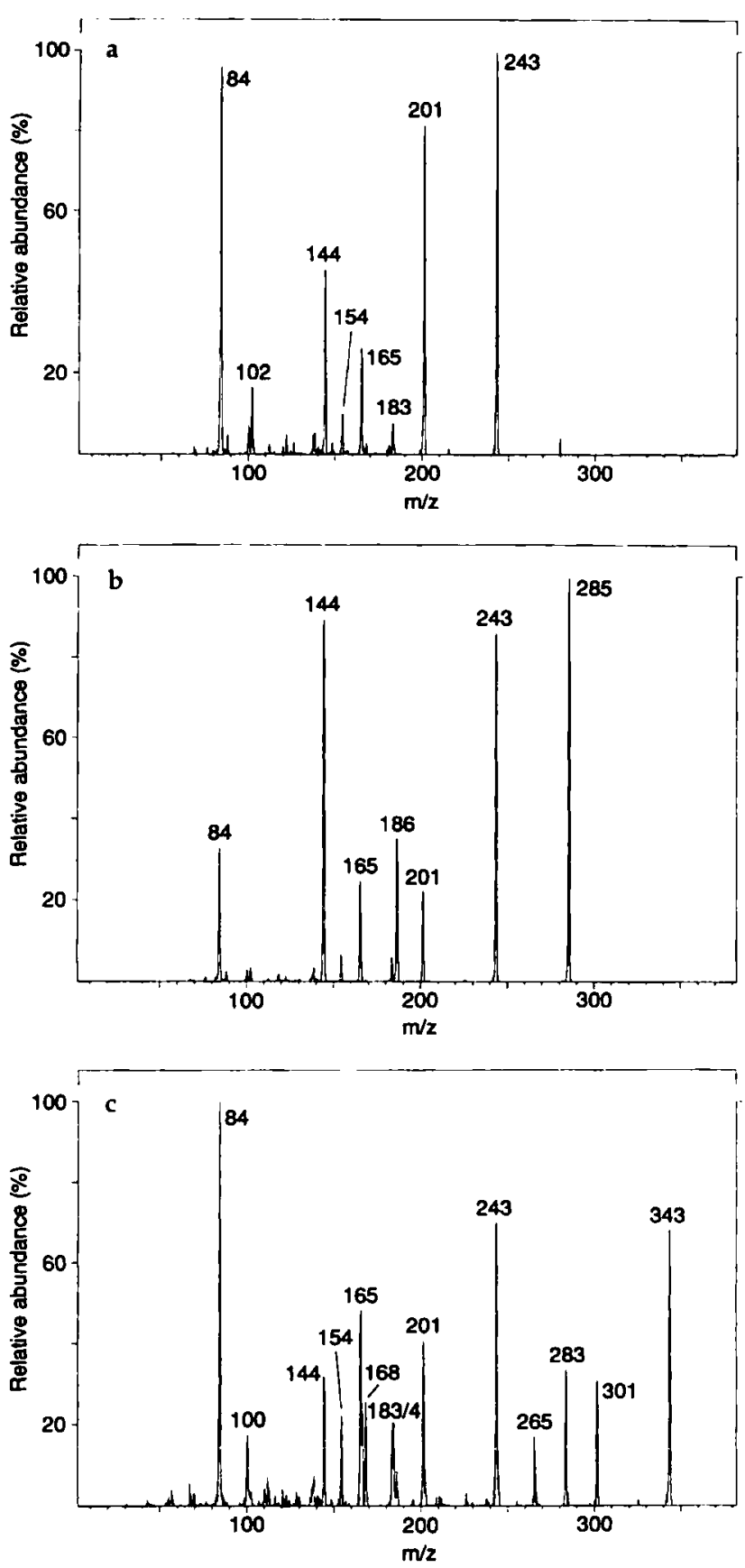

Figure 6. Product ion spectra of second generation fragment ions, that is, (a) $m / z 243$, (b) $m / z 285$, and (c) $m / z 343$, recorded during LC-ESI-CAD-MS/MS analyses; average of 8,30 , and 7 scans, respectively. For this purpose, the voltage difference between grounded skimmer and rf-only octapole was increased to $-30 \mathrm{~V}$. The overall collision energy $\left(E_{\mathrm{lab}}\right)$ was $40 \mathrm{eV}$ (apicid -30 $\mathrm{V}$, coff $-10 \mathrm{~V}$ ); the LC gradient was $2-92 \% \mathrm{~B}$ in $10 \mathrm{~min}$.

is, from both internal $\omega$-succinylamino- $N$-acetoxyaminopentane units. The corresponding product ion spectra of $m / z 285$ and 343, recorded during LC-ESICAD-MS-CAD-MS analyses, are shown in Figure $6 \mathrm{~b}$ and $c$. In addition to a-derived fragment ions (compare Figure 6a), the tandem mass spectra of the $\mathrm{m} / \mathrm{z}$ $343 / 285$ ions show evidence for the expected losses

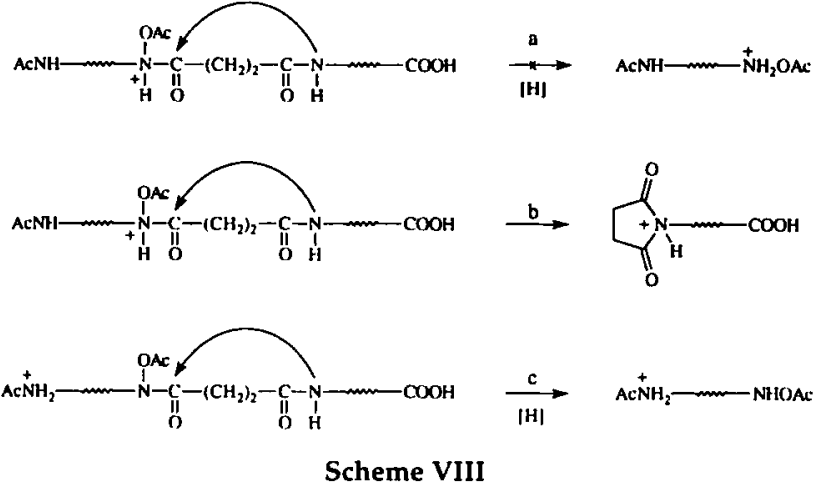

from the molecular ion of ketene (from the $N$-acetoxy moiety; $m / z 343$ to 301 and 285 to 243 ), acetic acid ( $m / z 343$ to 283 ), and succinimide $(\mathrm{m} / \mathrm{z} 343$ to 244 and 285 to 186 ).

\section{Proposed "Basic" Fragmentation Mechanisms}

Theoretically, several mechanisms of fragmentation at the hydroxamate bonds are conceivable (Scheme VIII; $[\mathrm{H}]$ indicates hydrogen transfer). They all feature a succinimide-mediated rearrangement, but differ with regard to whether they are charge-remote or chargedriven and whether they involve hydrogen transfer or not. Apparently not all these possibilities are realized. At the $N$-terminal hydroxamate bond, for example, charge-driven fragmentation under hydrogen transfer can be excluded (Scheme VIIIa). If it were to occur, then an ammonium ion $B_{1}^{\prime \prime}$ with $m / z 203$ should be observed, but it is not. Perhaps the absence of this pathway can be rationalized in terms of electrostatic repulsion between the "residing" proton and any other proton that might be a candidate for transfer. In contrast, the corresponding acylium fragment ion $Y_{5}$, which might be expected to arise from charge-driven fragmentation without proton transfer (Scheme VIIIb), is a prominent ion.

If the fragmentation of proferrioxamines were to proceed always in a charge-driven manner, and the "electrostatic repulsion" hypothesis were to apply in general, then no ammonium ions should be observed at all. However, as we have seen previously, the $\mathrm{B}_{3}^{\prime \prime}$ ammonium ion $(m / z 445)$ is prominent even under mild collision conditions (LC-ESI-MS; no forced CAD). A way to reconcile the existence of the $B_{3}^{\prime \prime}$ ammonium ion with the presumption that proton transfer during charge-driven fragmentation does not occur is to allow charge-remote fragmentation (Scheme VIIIc). Obviously, charge-remote fragmentations can only occur in larger ions, and then proton transfer is essential to create a good leaving group.

Charge-remote fragmentation appears to occur only at least a succinyldiaminopentane unit apart from any charge. The foregoing argument that otherwise we should observe a $m / z 203$ ion (Scheme VIIIc) also 
applies here. This fact may be rationalized, as illustrated in Scheme IX, via proton sharing between the free $N$-terminus or an amide nitrogen atom and its neighboring $C$-terminal hydroxamate nitrogen. For internal bonds, nucleophilic attack on the adjacent carbonyl groups could come from either an amide or hydroxamate nitrogen atom. However, as expected, attack of the more nucleophilic amide nitrogen atom is more successful. Evidence for such cyclic structures has been obtained for protonated diamines by ion mobility spectroscopy [26]. Protonation at the $N$ terminus or at amide nitrogen atoms thus is expected to induce charge-driven (but not charge-remote) fragmentation of the neighboring $C$-terminal hydroxamate bond.

By allowing competition between charge-driven fragmentation without proton-transfer (Scheme VIIIb) and charge-remote fragmentation with proton transfer (Scheme VIIIc), we feel that we can satisfactorily explain the characteristic fragmentation pattern of (peracetyl) proferrioxamines at very low collision energy ( $E_{\text {lab }}=15 \mathrm{eV} ; E_{\mathrm{cm}}=1 \mathrm{eV}$ ). In this manner, all the observed fragment ions $\left[\mathrm{B}_{3}^{\prime \prime}(\mathrm{m} / \mathrm{z} 445), \mathrm{Y}_{3}(\mathrm{~m} / \mathrm{z}\right.$ $343 / 285), Y_{5}(m / z 585 / 527)$, and the internal $m / z 243$ ion; Scheme VI] can be rationalized, and no fragment ions are predicted that are not produced.

Specifically, protonation at the $N$-terminal diaminopentane moiety followed by charge-driven fragmentation of the $N$-terminal hydroxamate bond will give rise to the $Y_{5}$ acylium ion $(m / z 585 / 527)$, whereas charge-remote fragmentation of the center hydroxamate bond will give rise to $B_{3}^{\prime \prime}(m / z 445)$. Subsequent charge-driven fragmentation of $\mathrm{B}_{3}^{\prime \prime}$ at the original $N$ terminal hydroxamate bond will produce the internal a $(m / z 243)$ ion. Subsequent charge-driven fragmentation of $Y_{5}$ will give rise to $Y_{3}(m / z 343 / 285)$, which then can loose the $C$-terminus to produce a or succinimide to produce c. Protonation at the central diaminopentane moiety may give rise to charge-directed fragmentation of the central hydroxamate bond, which leads to $Y_{3}$ directly. Succinimide-mediated fragmentation is not possible at the C-terminal hydroxamate bond, which provides a rationale as to why $B_{5}^{\prime \prime}$ and $Y_{1}$ ions are not seen. Finally, it is conceivable that protonation at the $C$-terminal diaminopentane moiety may lead to charge-remote fragmentation at the $N$-terminal hydroxamate bond. This would produce a fragment ion, say $Y_{5}^{*}$, that is isobaric with $Y_{5}$, but bears the charge on the $C$-terminal diaminopentane moiety rather than the succinimide ring. Keeping the cyclic protonated diaminopentane structure of Scheme IX in mind,

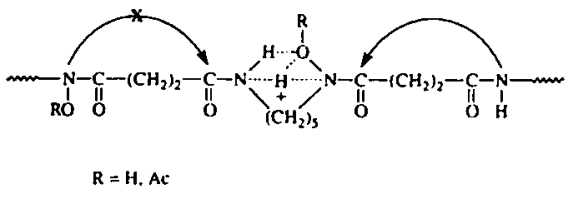

Scheme IX it may be assumed that $Y_{5}^{*}$ is more stable than $Y_{5}$, because a free nucleophilic amide nitrogen atom for succinimide-mediated fragmentation is not available.

\section{Terminal Group Effects}

In proferrioxamines with charged (or potentially charged) terminal groups such as in $\mathrm{pFO}_{555}$ and $\mathrm{pFO}_{555 \mathrm{Ac}}$, additional (presumably charge-driven) competitive fragmentation pathways become available (see preceding text). At this point, the terminal group effects are poorly understood. For example, a protonated $z$ witterion (Scheme $X$ ) may be invoked to rationalize charge-driven fragmentation at the $C$-terminal hydroxamate bond in $\mathrm{pFO}_{555}$. However, although the same mechanism theoretically also could apply to $\mathrm{Ac}_{4}-$ $\mathrm{pFO}_{555}$, facile fragmentation of the $\mathrm{C}$-terminal hydroxamate bond is only observed for $\mathrm{pFO}_{555}$, but not $\mathrm{Ac}_{4}-$ $\mathrm{pFO}_{555}$. It may require a free $\mathrm{N}$-terminus for substantial amounts of the zwitterion to be produced. A full mechanistic appreciation of the effects of terminal functional groups will require the study of additional acyclic proferrioxamines.

\section{Conclusion}

The foregoing results suggest that the characteristic fragmentation pattern of proferrioxamines (cyclic and acyclic) is due to preferential fragmentation at hydroxamate bonds. The fragmentation is obviously driven by energetically and sterically favorable succinimide formation and may be charge-driven (without proton transfer), to give the corresponding acylium ions, or charge-remote (with proton transfer), to give the corresponding ammonium ions. Once a hydroxamate bond is cleaved, the neighboring amide bond has become part of the newly formed succinimide ring and as such is protected from fragmentation. Cleavage of the inner hydroxamate bonds can proceed to give both the ammonium and acylium ions. Ammonium ion formation is not observed at the $N$-terminal hydroxamate bond, presumably due to formation of a cyclic protonated diaminopentane structure. Fragmentation of the Cterminal hydroxamate bond in most instances requires somewhat higher collision energy. Although loss of ketene or succinic anhydride is possible at this site, succinimide formation is not. The "basic" fragmentation mechanism of acyclic trihydroxamate proferrioxamines thus gives rise to only the $B_{3}^{\prime \prime}, Y_{3}, Y_{5}$, and internal $\omega$-succinimido- $N$-hydroxy-aminopentane fragment ions. However, this "basic" fragmentation mechanism obviously can be modified by additional functional groups.

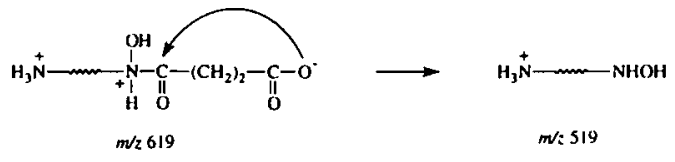

Scheme $X$ 


\section{Experimental}

Culture of Hafnia alvei. Hafnia alvei (ATCC 13337) was grown in the following chemically defined medium (Tris) that consisted of $5.8-\mathrm{g} \mathrm{L}^{-1} \mathrm{NaCl}, 3.7-\mathrm{g}$ $\mathrm{L}^{-1} \mathrm{KCl}, 1.1-\mathrm{g} \mathrm{L}^{-1} \mathrm{NH}_{4} \mathrm{Cl}, 0.15-\mathrm{g} \mathrm{L}^{-1} \mathrm{CaCl}_{2} \cdot 2 \mathrm{H}_{2} \mathrm{O}$, $0.1-\mathrm{g} \mathrm{L}^{-1} \mathrm{MgCl}_{2} \cdot 6 \mathrm{H}_{2} \mathrm{O}, 0.14-\mathrm{g} \mathrm{L}^{-1} \mathrm{Na}_{2} \mathrm{SO}_{4}, 0.28-\mathrm{g}$ $\mathrm{L}^{-1} \mathrm{KH}_{2} \mathrm{PO}_{4}, 15.9-\mathrm{g} \mathrm{L}^{-1}$ Trizma $\cdot \mathrm{HCl}, 100-\mu \mathrm{g} \mathrm{L}^{-1}$ nicotinic acid, and $2-\mathrm{g} \mathrm{L}^{-1}$ glucose. All chemicals were either analytical or tissue culture grade. Cultivation was in batches of $50 \mathrm{~mL}$ in $250-\mathrm{mL}$ Erlenmeyer flasks for four days at room temperature under moderate stirring (Bellco nine position magnetic stirrer, speed 4-5; Bellco Glass Inc., Vineland, NJ).

Preparation of extracts. After removal of bacterial cells by centrifugation at $8600 \mathrm{~g}$ for $20 \mathrm{~min}$, the supernatant was brought to dryness in $500-\mathrm{mL}$ flasks on a rotary evaporator with the water bath set at $40^{\circ} \mathrm{C}$. The dried residue was extracted twice with $50-\mathrm{mL}$ methanol, the methanolic extracts were combined, the methanol was removed by rotary evaporation, and the residue was dissolved in 2-mL water.

Isolation of proferrioxamine $\mathrm{pFO}_{555} . \quad \mathrm{pFO}_{555}$ was isolated by reversed-phase chromatography (Applied Biosystems Inc. [Foster City, CA] Spheri-5 ODS, $\mathrm{C}_{18}$ column, $2.1 \times 220 \mathrm{~mm}, 5-\mu \mathrm{m}$ particle size, fitted with a $30-\mathrm{mm}$ precolumn) on a Hewlett-Packard (Avondale, PA) 1090M high performance liquid chromatograph with binary DR5 solvent delivery system and diode array absorbance detector. A linear gradient of $10-40 \%$ B ( $B=90 \%$ methanol) in water over $40 \mathrm{~min}$, a flow rate of $200 \mu \mathrm{L} \mathrm{min} \operatorname{mon}^{-1}$, and detection at $215 \mathrm{~nm}$ were used. In this system, $\mathrm{pFO}_{(455)}$ and $\mathrm{pFO}_{555}$ eluted at about 33.5 and $36 \mathrm{~min}$, respectively, with almost baseline separation. In between runs, the column was washed for 5 min with $75 \%$ B. Chromatographic workup of a 1650$\mu \mathrm{L}$ extract, in 12 batches of 100 to $150 \mu \mathrm{L}$ each, yielded a total of $340-\mu \mathrm{g} \mathrm{pFO}_{555}$.

Capillary reversed-phase chromatography. Several versions of a capillary gradient system, which have been described elsewhere $[4,27,28]$, were used on-line with electrospray mass spectrometry. Capillary columns [450- $\mu \mathrm{m}$ o.d., $250-\mu \mathrm{m}$ i.d., $10-20 \mathrm{~cm}$ long, packed with 5- $\mu \mathrm{m}$ wide-pore $(300-\AA) \mathrm{C}_{18}$ ] were made from various sizes of fused silica capillary obtainable from PT Polymicro Technologies Incorporated (Phoenix, AZ) following published instructions [29]. Typically, the system was run at a flow rate of $2 \mu \mathrm{L} \mathrm{min}{ }^{-1}$ in the analyzing and at $20 \mu \mathrm{L} \mathrm{min}^{-1}$ in the sample loading mode. Neither eluent nor effluent was subject to "splitting." Injection volumes were on the order of 1-5 $\mu \mathrm{L}$. Gradients are given in the figure legends. To avoid possible clogging of the source-analyzer transfer capillary by salts, we routinely turn the electrospray on only after the void volumes of the chromatographic runs have passed.
Mass spectrometry. Mass measurements were made on Finnigan (San Jose, CA) TSQ700 triple stage quadrupole mass analyzers coupled to DEC 2100 or DEC 5000 workstations (Digital Equipment Corp., Maynard, MA). For operation in the liquid secondary ionization mass spectrometry (SIMS) mode, a retrofitted cesium ion source (Phrasor Scientific Inc., Duarte, CA) was used. Electrospray was performed either with a Finnigan-upgraded Analytica of Branford (Branford, CT) or the new Finnigan-designed source as indicated. Except for the deuterium exchange studies, a liquid sheath flow of $2 \mu \mathrm{L} \mathrm{min}^{-1} 2$-methoxyethanol was used. Nebulization also was assisted by a gas sheath flow of $35-60-\mathrm{lb}$ in. ${ }^{-2} \mathrm{~N}_{2}$. The electrospray voltage was set at 4-5 kV. In the Finnigan source, the source-analyzer transfer capillary was held at $200{ }^{\circ} \mathrm{C}$. Except for the product ion spectrum of $\mathrm{pFO}_{555 \mathrm{Ac}}$, which was obtained with 8- and 2-u wide peaks in $\mathrm{Q}_{1}$ and $\mathrm{Q}_{3}$, respectively, both quadrupoles were tuned to unit mass resolution (full width at half height). Collision gas was argon at 2-3 millitorr (0.27-0.4 Pa). The approximate collision energy $\left(E_{\mathrm{Lab}}\right)$ was calculated as the product of the charge of the ions (in this study always +1 ) times the collision cell offset voltage $\left(c_{\text {off }}\right)$. For collision activation at the atmosphere-analyzer interface (between grounded skimmer and rf-only octapole before MS-1), all potentials after the skimmer, including $c_{\text {off }}$, were lowered by $-30 \mathrm{eV}$ ("apicid $30^{\prime \prime}$ ). The collision energy in $Q_{2}$ was thus automatically increased by the same numerical value. Most spectra represent an average of 5-32 scans as indicated. The mass analyzer was continuously cycled with an approximate scan rate of $400 \mathrm{u} \mathrm{s}^{-1}$.

Acetylation. The peracetyl $\left(\mathrm{Ac}_{4}\right)$ derivatives were obtained by treatment overnight at room temperature of $20-\mu \mathrm{g} \mathrm{pFO}_{555 \mathrm{Ac}}$ or $9-\mu \mathrm{g} \mathrm{pFO}_{555}$ with $50-\mu \mathrm{L}$ acetic anhydride in $50-\mu \mathrm{L}$ pyridine. The reaction mixture was used directly for LC-ESI-MS (1 $\mu$ L injected), LC-ESIMS/MS, or LC-ESI-CAD-MS/MS ( $5 \mu \mathrm{L}$ injected).

Hydrogen / deuterium exchange. For the liquid SIMS experiment, $\mathrm{H} / \mathrm{D}$ exchange was performed on the probe. Approximately $1-\mu \mathrm{L}$ glycerol was placed on the probe, $1-\mu \mathrm{L}_{2} \mathrm{O}$ was added, and the water was removed in the roughing vacuum. The $\mathrm{D}_{2} \mathrm{O}$ treatment was repeated three times, then $1 \mu \mathrm{L}$ of the sample solution (340- $\mu \mathrm{g} \mathrm{pFO}_{555}$ in $500-\mu \mathrm{L} \mathrm{D}_{2} \mathrm{O}$ ) was added, and the sample immediately was subjected to tandem mass spectrometric analysis. The conventional mass spectrum confirmed that fully deuterated glycerol $(\mathrm{m} / \mathrm{z}$ 97) and $\mathrm{pFO}_{555}(\mathrm{~m} / \mathrm{z}$ 628) were the major components. For comparison, the corresponding experiment also was performed with ESI-MS via the upgraded Analytica electrospray source. One milliliter of 2methoxyethanol was treated with $5-\mathrm{mL} \mathrm{D}_{2} \mathrm{O}$ and $1-\mu \mathrm{L}$ acetic acid, and the water was removed on a rotary evaporator. Treatment with $5-\mathrm{mL} \mathrm{D}_{2} \mathrm{O}$ was repeated 
three more times and the $D_{1}$-2-methoxyethanol then served as the liquid sheath in the usual manner. Batch infusion of the $\mathrm{pFO}_{555}$ sample (same as for liquid SIMS) and the liquid sheath was performed with a syringe infusion pump (model 22, Harvard Apparatus, South Natick, MA) operated at $2 \mu \mathrm{L} \min ^{-1}$. A conventional mass spectrum confirmed that fully deuterated 2-methoxyethanol $\left(m / z\right.$ 79) and $\mathrm{pFO}_{555}(\mathrm{~m} / \mathrm{z}$ 628) were the major components. The same fragmentation pattern and a similar signal-to-noise ratio as in the liquid SIMS experiment were observed. Sample and $\mathrm{D}_{2} \mathrm{O}$ consumption was considerably larger in the ESI mode, however, and, at the time, the liquid SIMS method was preferred over the ESI method. On the other hand, with hindsight it appears that dilution of the sample by a factor of 1000 may have been possible and actually beneficial, because the $\mathrm{pFO}$ concentration was in the millimolar range and thus above the saturation point for electrospray [30].

\section{Acknowledgments}

This work was supported by a Beckman Research Award from the City of Hope (to GJF), a Summer Undergraduate Research Fellowship (SURF) from California Institute of Technology (to LLH), and NIH Cancer Center Core Grant CA33572. The authors wish to thank Dr. T. D. Lee for his support as well as his constructive criticism and Dr. T. Schupp, Ciba Geigy, Basel, for a sample of $\mathrm{pFO}_{555 \mathrm{AC}}(\mathrm{pFO} B$ ).

\section{References}

1. Feistner, G. J. Biol. Mass Spectrom. 1994, 23, 793.

2. Gross, K.; Aumiller, J.; Gelzer, J. Desferrioxamine. History, Clinical Value, Perspectives; MMV Medizin-Verlag: München, 1992.

3. Pochon, S.; Buchegger, F.; Pelegrin, A.; Mach, J.-P.; Offord, R. E.; Ryser, J. E.; Rose, K. Int. J. Cancer 1989, 43, 1188.

4. Feistner, G. J.; Stahl, D. C.; Gabrik, A. H. Org. Mass Spectrom. 1993, 28, 163.

5. de Hoffmann, E.; Stroobant, V. Biol. Mass Spectrom. 1991, 20 , 142.
6. Feistner, G. J. BioMetals 1995, 8, 193.

7. Hunt, D. F.; Yates, J. R. I.; Shabanowitz, J.; Winston, S.; Hauer, C. R. Proc. Natl. Acad. Sci. USA 1986, 83, 6233.

8. Biemann, K.; Martin, S. A. Mass Spectrom. Rev. 1987, 6, 1.

9. Kenny, P. T. M.; Nomoto, K.; Orlando, R. Rapid Commun. Mass Spectrom. 1992, 6, 95.

10. Mueller, D. R.; Eckersley, M.; Richter, W. J. Org. Mass Spectrom. 1988, 23, 217.

11. Arnott, D.; Kottmeier, D.; Yates, N.; Shabanowitz, J.; Hunt, D. F. Proceedings of the 42 nd ASMS Conference on Mass Spectrometry and Allied Topics; Chicago, Illinois, 1994; $\mathrm{p} 470$.

12. Tomer, K. B.; Crow, F. W.; Gross, M. L. J. Am. Chem. Soc. 1983, 105, 5487.

13. Jensen, N. J.; Tomer, K. B.; Gross, M. L. J. Am. Chem. Soc. 1985, 107, 1863.

14. Adams, J. Mass Spectrom. Rev. 1990, 9, 141.

15. Adams, J.; Songer, M. J. Trends Anal. Chem. 1993, 12, 28.

16. Rubino, F. M.; Zecca, L.; Sonnino, S. Biol. Mass Spectrom. 1994, $23,82$.

17. Wysocki, V. H.; Ross, M. M. Int. J. Mass Spectrom. Ion Processes 1991, 104, 179.

18. Cody, R. B. Rapid Commun. Mass Spectrom. 1988, 2, 260.

19. Wheelan, P.; Zirrolli, J. A.; Murphy, R. C. Biol. Mass Spectrom. 1993, 22, 465.

20. Alexander, A. J.; Thibault, P.; Boyd, R. K. Rapid Commun. Mass Spectrom. 1989, 3, 30.

21. Chang, Y. S.; Gage, D. A.; Watson, J. T. Biol. Mass Spectrom. 1993, 22, 176.

22. Roepstorff, P.; Fohlman, J. Biol. Mass Spectrom. 1984, 11, 601.

23. Reissbrodt, R.; Rabsch, W.; Chapeaurouge, A.; Jung, G.; Winkelmann, G. Biol. Metnls 1990, 3, 54.

24. Tang, X. J.; Boyd, R. K. Rapid Commun. Mass Spectrom. 1992, 6,651 .

25. Renner, D.; Spiteller, G. Biomed. Environ. Mass Spectrom. 1986, 13, 405.

26. Karpas, Z.; Bell, S. E.; Wang, Y. F.; Walsh, M.; Eiceman, G. A. Struct. Chem. 1994, 5, 135.

27. Stahl, D. C.; Davis, M. T.; Lee, T. D. Proceedings of the 42nd ASMS Conference on Mass Spectrometry and Allied Topics; Chicago, Illinois, 1994; $\mathrm{p} 487$.

28. Davis, M. T.; Stahl, D. C.; Lee, T. D. I. Am. Soc. Mass Spectrom. 1995, 6, 571.

29. Davis, M. T.; Lee, T. D. Protein Sci. 1992, 1, 935.

30. Feistner, G. J. Am. Lab. 1994, 26, 32. 